Review

\title{
The Relationships between Symmetry and Attractiveness and Mating Relevant Decisions and Behavior: A Review
}

\section{T. Joel Wade}

Department of Psychology, Bucknell University, Lewisburg, PA, 17837, USA;

E-Mail: jwade@bucknell.edu

Received: 30 April 2010; in revised form: 8 May 2010 / Accepted: 24 May 2010 /

Published: 26 May 2010

\begin{abstract}
Evolutionary theory based research shows that attractiveness is based on biological correlates that index appropriate estrogen and testosterone levels. Symmetry affects or plays a role in the perception of many of these correlates of attractiveness. Additionally, since attractiveness affects infidelity perception and reactions, sexual satisfaction, and personality perception, symmetry also affects these areas. This paper reviews the literature on symmetry showing how symmetry affects: the correlates of attractiveness, sexual satisfaction, personality, and infidelity perceptions and reactions.
\end{abstract}

Keywords: symmetry; attractiveness; attraction; mating decisions

\section{Introduction}

The results from prior research indicate that evaluations of physical and sexual attractiveness can be guided by the execution of evolutionary adaptations based on finding the "best" mate and producing the "best" offspring [1-16]. Individuals focus on reproductively relevant characteristics of the male and female body and face in order to determine if the individual being rated is attractive and most reproductively fit (likely to be reproductively successful). Consequently, attractiveness can be based on facial and bodily characteristics that index sexual maturity, gender identity, and phenotypic quality on facial and bodily characteristics that index sexual maturity, gender identity, and phenotypic quality [15-17]. Developmental stability also plays a role. Fluctuating asymmetry is an intrinsic property of an individual's genome that provides an honest signal of individual quality [18]. Thus, it also influences an individual's identification of the "best" mates. This paper points out the correlates of attractiveness for men and women, and then reviews the literature on symmetry and attractiveness, and symmetry 
and mate relevant decisions and behavior to show how symmetry relates to or affects the correlates of attractiveness and mate relevant decision making and behavior.

\subsection{Sex Differences in Attractiveness Determinants}

Since attractiveness has a biological basis, the characteristics of facial and bodily attractiveness differ somewhat for men and women. Men's attractiveness is based on facial and body characteristics signaling dominance, status, masculinity, and good health [2-4,7-9,11,15-17,20]. Therefore, men with high status and/or dominance and masculinity-related facial and body characteristics are considered most physically and sexually attractive and the best choices to ensure reproductive success. Testosterone and areas of the body indexing testosterone play key roles.

Dominant males have higher testosterone levels [21-23] and the size of men's chests, biceps, their muscular strength, and the size, shape, and tone of their physiques are characteristics influenced by testosterone [24]. Thus, men with broad chests, muscular upper bodies, and smaller waists are considered more dominant and more attractive [11,23,25,26]. Additionally, sexual activity is also related to testosterone levels. Therefore, given that dominant males have more testosterone, research shows that they copulate more frequently [20,27]. Similarly, dominant men are also said to have stronger sex drives due to increased testosterone levels [23].

Chin breadth is also a testosterone-mediated characteristic [17,28]. Thus, dominant men have broader chins and are considered more attractive [20,29]. This may be because pathogen resistance [30-32] is indexed by human chin length. One other facial characteristic, nose size, is also affected by testosterone. Nose size is a sexually dimorphic characteristic signaling gender identity [17]. Men typically have larger noses than women because men have more testosterone. Thus, nose size can be used to make inferences regarding whether or not one is male or female.

Stomach size and shape can also be a product of testosterone. Specifically, the size and shape of a man's stomach is the product of android fat deposits [10,11,24,33,34]. Thus, stomach size is also an important characteristic, and men with smaller/less fat stomachs are considered more attractive and healthier [24-26,33,34]. Additionally, good physical condition and muscular development are associated with testosterone, dominance, and physical prowess [23] and these factors also play a role in attractiveness assessments.

Women's attractiveness and reproductive success are based on cues from facial and body characteristics that signal fecundity, successful mothering potential (the ability to most successfully raise offspring independent of the ability to become pregnant), femininity, and pathogen resistance [2-7,9,10,12-17].

The most important and most visible physical cue for women is the waist-to-hip ratio (WHR) $[13,17]$. The WHR is related to crucial endocrine states associated with fecundity and successful mothering, and femininity is inferred from it $[9,10,12]$. This is due to gynoid fat being distributed on the thighs, legs, buttocks, waist, and hips of women [9,12,23]. Women who appear to have small hips, small waists, medium to small buttocks, and medium legs [35] are considered more attractive, healthier, more feminine, most fertile, and better potential mothers [9-12,14,17]. Additionally, women's waist size is an indicator of their risk for disease, is used to assess their hormonal status, and 
is correlated with cardiovascular disorders, diabetes, and gall bladder problems $[14,36]$. But, is WHR the best predictor of attractiveness?

Some researchers suggest that an attractiveness assessment based on WHR is a product of changes in BMI such that BMI is a better predictor of female attractiveness than WHR [37,38]. However, recent research, using photographs of pre and post surgical patients, comparing the contributions of WHR and BMI to women's attractiveness assessments, reports that women with lower WHR are rated as more attractive regardless of changes in their BMI $[39,40]$.

Cheekbone breadth and size are also evolutionary relevant characteristics. Women with high cheekbones are considered more attractive, more feminine, healthier, and more fertile [2,4,17]. This is due to women's cheekbone size indexing pathogen resistance [30-32]. Women's breasts and the appearance of their stomachs also play a role [9,10,12-14,17]. This is because gynoid fat is distributed on the abdomens of women $[9,10,12,24]$, and women with large breasts are considered more attractive, more feminine, healthier, and most desirable for long- and short-term relationships [14].

Lip size also plays a role because lip size is also an estrogen-mediated trait [41] and an indicator of femininity and attractiveness [17]. The size of a woman's eyes is also important. However, the eyes are not estrogen-mediated characteristics. But, the eyes get smaller with age [15]. So, eye size becomes a heuristic for youth and fertility. Not surprisingly, then, women with large round eyes are considered more attractive, more fertile, and healthier [2,4,17]. Physical condition is important as well. This is because good physical fitness is related to fecundity [42,43] and may also signal phenotypic quality [17].

In addition to the facial and bodily components delineated above, attractiveness is also a product of pheromones [44], height [45,46], vocal quality [47-49] pupil size [50,51], hair length and quality [52,53], leg length [54], and foot size [55]. These attractiveness foci are also the product of evolutionary adaptations designed to help one select the best mate. But, what about developmental stability?

\section{Discussion}

\subsection{Developmental Stability}

Since attractiveness is based on biological adaptations predicated on producing the best offspring one would assume that individuals would want to select partners who seem to be the products of a stable development as this might best insure the production of the most healthy offspring. So, developmental stability should play a role. Developmental stability refers to the capacity of an individual to produce a well developed symmetrical phenotype in the face of developmental perturbations caused by disease, toxins, parasites, etc. [56]. Since symmetry of the face and body indexes developmental stability [57,58], research indicates that symmetry does play a role in mate assessment. Prior research indicates that departures from symmetry reflect an individual's incapacity to maintain developmental homeostasis [29,59,60]. Thus, not surprisingly, since sexual selection favors those traits that indicate the ability to withstand parasites [61], research shows that symmetry affects the perception of many of the correlates of attractiveness delineated above. Preferences for a symmetrical mate may have evolved because of positive genetic effects on offspring survival [57]. 


\subsection{Facial Symmetry and Facial Attractiveness}

As mentioned above, many aspects of the face play a role in attractiveness judgements. Aesthetic judgements of faces are not capricious, but reflect evolutionary functional assessments of potential mates [57]. Research examining facial symmetry shows that overall symmetry of the face does influence perceptions of the face. But, why would facial symmetry be important?

Since the face displays secondary sexual characteristics facial symmetry is more sensitive to environmental perturbations [57]. Facial asymmetry is located in various sites in the face [62]. Consequently, facial symmetry functions like a certificate of health with regards to mate potential [63]. Women are seen as more attractive when their faces are symmetrical and close to average [63]. Asymmetric divergences away from average may indicate environmental perturbations during development, genetic problems or psychological distress. In addition, facial symmetry predicts facial attractiveness and facial attractiveness is a reliable indicator of developmental stability [64]. Thus, facial attractiveness of both sexes signals genetic quality in the form of developmental stability [64]. Additionally, facial symmetry is correlated with attractiveness in both men and women [65]. Selecting a genetically distinct/diverse mate can facilitate an offspring's ability to resist parasites. Consistent with that, preferences for symmetry may be a mate choice adaptation rather than a byproduct of strategies used to process visual stimuli [65]. So, facial symmetry is important for attractiveness evaluations for adaptive reasons. Consistent with this, facial symmetry displays underlying genetic diversity and parasite resistance and consequently, a symmetrical face displays developmental homeostasis [66]. Similarly, symmetrical faces are judged as healthier than asymmetrical faces and this relationship remains even after the effect of attractiveness is partialed out [67], showing that humans have an adaptive preference for faces that signal quality. In addition, the preference for facial symmetry is not due to perceptual preference [68]. Rather, it is due to an evolutionary adaptation to facilitate mate selection. Thus, there is cross cultural agreement on the attractiveness of symmetry [69]. Clearly, the preponderance of research indicates that facial symmetry is important for attractiveness and mate selection decisions. But what about the body? Does symmetry of the body affect attractiveness?

\subsection{Body Symmetry and Attractiveness}

Research has examined the symmetry of individual parts of the body and overall symmetry of the body. Body symmetry is a major correlate of attractiveness [70]. Similarly, attractiveness for women is related to body symmetry [71]. More recently, researchers have reported that overall asymmetry is related to attractiveness for both men and women [64]. For women, this is due to symmetry's relationship to reproductive potential. Overall asymmetry is related to reproductive potential in women [72,73]. Higher symmetry leads to greater reproductive potential. In addition, for both men and women this relationship between body symmetry and attractiveness most likely occurs due to symmetry's reflection of overall quality of development. Research with animals indicates that symmetry reflects the overall quality of development [61,70,74,75]. Thus, similarly, overall body symmetry in humans plays a role in attractiveness evaluations. But, is this true for specific parts of the body that are evolutionarily significant with respect to attractiveness evaluation. 


\subsection{Breast Symmetry}

Recent directional selection has played a role in the evolution of adult female breast size [73]. Furthermore, the rapid development of breasts prior to and during puberty and their role in interactions between men and women indicates that the breasts may play a role in sexual selection [73,76,77]. This is not surprising because breasts are secondary sexual characteristics, and secondary sexual characteristics play a role in determinations of whether or not an individual is sexually mature, male or female, and can create and best care for children [15,16]. Also, breasts signal mate quality [78-80]. Since developmental stability also signals mate quality and developmental stability is indexed by symmetry and the breasts signal mate quality, one might assume that the symmetry of women's breasts also plays a role in assessments of their mate quality. In fact, breasts are expected to demonstrate higher levels of developmental instability than other body parts [81]. Also, breast symmetry is large compared to other structural characteristics of the body [73]. Thus, breast symmetry should play a role in mate choice related adaptations.

In line with the aforementioned assumption, experimental research, shows that breast asymmetry does play a role in aspects of mate quality. Specifically, breast asymmetry plays a role in attractiveness and health judgements [82]. Additionally, research that incorporates actual measurements of breast symmetry in US and Spanish samples finds that breast asymmetry is negatively correlated with the number of children women have [73]. Women with symmetrical breasts have more children. While there may be additional reasons for this, one reason this may occur is because these women are rated as more attractive and consequently are selected for mating more often. Choosy men who use breast symmetry as a cue for mate selection will experience an advantage in terms of reproductive success [73]. Also, since breast symmetry is heritable [73,78] these men gain a selection advantage because their daughters should experience higher mating success and fecundity [73]. So, one can conclude that breast symmetry is a reliable signal of reproductive potential [73]. Clearly, facial, overall body symmetry, and breast symmetry play a role in attractiveness related judgements. But, does symmetry affect other correlates of attractiveness? Since symmetry indexes developmental stability and attractiveness it should also affect other body characteristics used to make attractiveness judgements.

\subsection{Vocal Quality}

Both correlational and experimental research shows that vocal quality influences attractiveness assessments. Men with lower pitched voices are considered more attractive and more masculine $[47,49]$ and women with higher pitched voices are considered more attractive and more feminine [48]. Additionally, female vocal quality is associated with facialmetric assessments of femininity [84]. Also, men and women with attractive voices tend to have more sexually dimorphic body configurations that reflect activational hormone exposure seen at puberty [85]. Men with attractive voices had broader shoulders and women with attractive voices had hourglass figures [85]. This further indicates that vocal quality is associated with development and developmental stability.

Vocal pitch is one vocal quality associated with development that has been examined due to its developmental significance. Vocal pitch changes as one reaches puberty due to the hormonal changes that occur $[48,86-88]$. The size and thickness of the vocal folds determine the fundamental frequency 
(pitch) of the voice: thicker vocal folds give rise to a lower voice. [48,87]. Males' vocal chords thicken and increase in size and their voices become deeper [47,49] and women's voices become higher at puberty [48]. So, pitch can indicate the general hormonal state and age of a speaker [48]. Since the voice changes with development, developmental stability is important for mate selection, and symmetry indexes developmental stability, vocal quality should be related to developmental stability. Indeed, individuals with voices rated as attractive have bilateral body traits that are more symmetrical [89]. As symmetry increases, ratings of vocal attractiveness increase [89]. So, vocal quality is associated with symmetry. What about other attractiveness cues?

\subsection{Pheromones}

Olfactory cues produced by men play a major role in the human sexual selection system [90]. Women's sexual attractiveness is more influenced by male scent than by visual features [91,92]. This is because women are extremely sensitive to Androstenol and men produce more of this than women do [93,94]. The male pheromone can signal immunocompetence [95]. So, pheromones can function as indices of developmental stability. With that in mind, one would expect symmetry to be related to pheromones since symmetry indexes developmental stability. Research has indeed found that symmetry is related to pheromone production in men. In research where women were asked to smell the t-shirts of men, women rated the t-shirts of symmetrical men as more attractive [96]. This effect is even stronger when the effect of bathing by the men is controlled for [97]. This preference for the scent of symmetric men is strongest when women are in the fertile phases of their menstrual cycles [90,98]. In addition to affecting attractiveness decisions, symmetry also plays a role in behavior related to attractiveness.

\subsection{Mate Protection}

One type of parental investment that women desire from male partners is a parental investment that affords them and their offspring protection [99]. Symmetrical men are perceived as better protectors of their mates than asymmetric men [100]. This may be because symmetric men are healthier [62,101-103] and consequently better equipped to fend off attacks. Additionally, since symmetry is associated with cognitive ability [104-106] symmetrical men may be better able to outsmart attackers, thus affording protection to their mates and offspring. Similarly, symmetrical men by virtue of their intelligence may fare better in employment contexts which would afford them a better ability to buy protection for their mates and offspring. Thus, the relationship between symmetry and mate protection. However, while these men with low facial asymmetry (FA) have better genes such that they are better protectors and more intelligent, they are not better fathers than high FA men since low FA men are more likely to commit adultery [100] (more detail regarding infidelity is presented later in this paper).

\subsection{Human Female Orgasm}

Women can exert a choice adaptation designed to manipulate sperm competition, promote conception with men of high quality, retain the sperm of high quality sires, and promote, create, and maintain a pair bond with men $[107,108]$. That choice adaptation is the female orgasm. The orgasm is not needed for conception $[107,109]$. But, it can enhance the likelihood of conception via the up-suck 
hypothesis where orgasmic contractions force the mouth of the uterus into the pool of sperm deposited in the vagina upon ejaculation [109]. Evolutionarily, women benefit from having offspring with males of high quality. So, male attractiveness plays a role in female orgasmic responses [108]. Since attractiveness plays a role in orgasmic responses and symmetry is related to attractiveness, symmetry should also play a role in human female orgasm. A study with 86 heterosexual adult couples, found that women with men who possessed low fluctuating asymmetry of the body self-reported and were reported by their partners to have had more orgasms during copulation than women with men possessing higher fluctuating asymmetry [108]. Additionally, women with men of low fluctuating asymmetry of the body did not simply have more orgasms in general than other women [108]. Rather, these women are only more orgasmic during copulation. Also, women's self-reports of their orgasmic behavior and their partner's reports of their orgasmic behavior correlated near .60 and the correlation between averaged reports and the true rate of orgasm was 0.85 [108]. So, these findings can be considered very valid. Symmetrical men may also provoke more orgasms because symmetrical men have higher quality sperm.

\subsection{Sperm Quality}

Women find men with good genes appealing [110] and symmetry indexes good genes. Sperm quality is also an index of good genes. So, symmetry is also associated with sperm quality. In a study of 53 men from a fertility clinic, men with higher symmetry in digits 2 to 5 were found to produce more sperm per ejaculate, have faster sperm, and have sperm that are better migrators [111]. Additionally, men with greater overall symmetry produce more sperm per ejaculate and have faster sperm [111]. Similarly, in a study including 34 men not being treated for infertility, men with greater symmetry of the second digit, ears, wrists, and ankles were found to have more sperm per ejaculate than men with lower symmetry [112].

\subsection{Sexual Behavior}

Attractive individuals have better sex lives [113] and they are preferred as sexual partners [19]. Since attractiveness and sexual behavior are associated, symmetry should also be associated with sexual behavior. Indeed, in a study with 122 participants, overall symmetry was found to predict the lifetime number of sexual partners, i.e., men with symmetric body measures attract more sexual partners [114]. Additionally, this effect remains after attractiveness is partialed out [114]. This effect is most likely due to a choice adaptation by women designed to control the quality of their offspring since symmetry is heritable [56,115]. Symmetry also affects age of first intercourse for men. Men with higher symmetry report having their first intercourse at an earlier age than men with less symmetry [114].

\subsection{Infidelity}

Both married men and married women engage in sex with individuals other than their partners, i.e., extrapair copulations (EPCs). Estimates place the rate of cheating among women at $15 \%$ to $70 \%$ with a median of $30 \%$ [100,116-118] and at 25\% to 50\% for married men [118-120]. One of the reasons men engage in EPCs is because EPCs may increase their quantity of offspring. According to sexual 
strategies theory [19] men prefer short term mating because it allows them to increase their probability of having offspring with many women and consequently getting their genes into the future population. Long term mating with one woman can lead to significant mating costs with no guaranteed payoff of offspring. So, men prefer short term mating. EPCs are short term matings where effort put toward the mating is small [100]. So, short term mating does not have the same costs for men that long term mating has. One of the reasons women engage in EPCs is because EPCs may increase the quality of their offspring. Potentially, women may be able to achieve genetic benefits as well as investment by engaging in EPCs [107,121].

Individuals want mates who can resist pathogens and parasites [62]. One marker of pathogen resistance is symmetry. Developmental quality, high symmetry, is associated with high mating success [114]. So, EPC partners should exhibit developmental stability if individuals want mates that are more pathogen resistant. In a study with 203 heterosexual couples, high symmetry was found to predict men's number of EPC partners, and men with high symmetry were selected as EPC partners more often than men with low symmetry [100]. Additionally, this is independent of men's number of sex partners other than EPC partners, and the effect exists when age, sex, SES, salary, attractiveness, and attachment style are controlled for [100]. Also, men with high symmetry are more likely to pursue EPCs than men with low symmetry [100]. These men may be more motivated to pursue a short term mating strategy.

\subsection{Athletic and Talent Displays}

One of the ways men and women attract mates is through intersexual and intrasexual competition [122,123]. This competition takes place via display behavior where both sexes try to display the attributes that the opposite sex prefers. Since men place an emphasis on women with high reproductive fitness, femininity, and successful mothering potential $[15,16,99]$ women display these attributes. They dress in ways that emphasize the body parts that index these attributes [124-126]. Since women desire men who are dominant, and socially ascendant $[15,16,99]$ men display these attributes. They dress and behave in ways that indicate that they are dominant, financially successful, or industrious [122,123].

Dominance and industriousness are products of testosterone [20-22] and testosterone influences developmental stability [110]. One way men can display their dominance is via athletic ability. So, there should be a relationship between athletic ability and symmetry. A study including 50 men, controlling for age and experience, found that there is a relationship between athletic ability and symmetry, i.e., faster middle distance runners have more symmetric ears and nostrils than slower runners [127].

The ratio of the index and ringer fingers, $2 \mathrm{D}: 4 \mathrm{D}$, also plays a role. This ratio is an index of prenatal testosterone $[128,129]$ and a smaller ratio indicates a higher level of prenatal testosterone. The ratio is fixed in-utero by the end of the 14th week (130-132). The 2D:4D ratio is assessed by measuring the index and ringer fingers from tip of the finger to the proximal crease where the finger meets the palm, and then diving the index finger length by the ringer finger length [133-135]. Since testosterone influences developmental stability [110], not surprisingly, 2D:4D is also linked to developmental stability and athletic and musical ability. 
A study with 304 soccer players, found that first team athletes have lower 2D:4D than reserves and professional athletes have lower 2D:4D than controls [133]. Similarly, studies with 468 total participants, report that individuals with lower 2D:4D have better physical fitness [136]. Additionally, a study of 70 musicians and 164 controls, found that lower 2D:4D is associated with musical ability such that men with lower 2D:4D occupy higher positions in their instrument sections [137]. So, since 2D:4D indexes athletic ability, musical ability, and developmental stability, not surprisingly then, it is also related to attractiveness. Men with lower 2D:4D are rated higher in attractiveness than men with higher 2D:4D [138,139]. Women with higher 2D:4D are also rated as more attractive than women with lower 2D:4D [140]. Since 2D:4D indexes developmental stability and attractiveness it should be related to symmetry. A study including 69 men, found that 2D:4D is negatively correlated with facial asymmetry [141]. Individuals with lower 2D:4D had more symmetrical faces.

As mentioned above, one of the ways men and women attract mates is through intersexual and intrasexual competition and display behavior where both sexes try to display the attributes that the opposite sex prefers [122,123]. In addition to displays of musical and athletic ability, another way that humans can display their fitness is via dancing. Dance may be a sexually selected courtship signal [142]. Also, symmetry is associated with locomotory traits or their functional effectiveness in humans [143]. Dancing involves locomotion. So, dancing should be a way to reveal genetic or phenotypic quality, i.e., developmental stability, to potential partners. It should be related to symmetry since symmetry indexes developmental stability and is associated with locomotory traits. A study with 183 dancers using motion capture technology, found that symmetrical men were perceived as better dancers than asymmetrical men [143]. Similarly, symmetrical women were perceived as better dancers than asymmetrical women. But, female symmetry accounted for $23 \%$ of the variance in dancing ability while male symmetry accounted for $48 \%$ of male dancing ability [143]. Also, women had a stronger preference for symmetrical male dancers while men preferred symmetrical and asymmetrical female dancers equally. Additional research [144] also finds that men described as dancers are rated as more attractive while descriptions of a woman as a dancer or not have no effect on attractiveness ratings of a woman. So, dancing is also a way to reveal developmental stability.

\subsection{Personality}

Personality plays a role in mate selection. The most important Big- 5 personality characteristics for mate selection are Agreeableness and Openness [145]. Often decisions about the personality of others are made without knowing anything about the individual other than what they look like, i.e., by looking at their face [146,147]. Additionally, 75\% of students tested believe the face is a valid guide to character [146]. The personality decisions based on the face show a high level of consensus among judges, with greater than chance accuracy also [148]. Configural properties of the face are used to make these personality decisions. Symmetry is a configural property of the face. So, symmetry plays a role in personality assessments also. A study with 146 men and 146 women, found a significant positive association between extraversion and symmetry of the face using a landmark measure of the face that includes peripheral regions of the face for both men and women [149]. Men and women with more symmetrical faces are more extraverted. Also, in a study examining a set of faces which all had valid personality measures available, Extraversion was found to be positively related to facial 
symmetry and Openness and Agreeableness were negatively related to facial symmetry [150]. Additionally, a study that included faces with unknown personality profiles and guesses about the personalities of the individuals found that facial symmetry is negatively related to Neuroticism, Agreeableness, and Conscientiousness [151]. Clearly, facial symmetry is a correlate of personality.

\subsection{Emotional and Psychological Health}

Evolutionary theory based research shows that individuals want mates who are healthy. Consequently, facial and bodily characteristics that index health and fitness are used to determine whether or not an individual is attractive $[15,16,99]$. As mentioned previously, since developmental stability can indicate fitness, it is given considerable attention. Thus, symmetry is also related to psychological and emotional health. Psychopathic individuals have greater symmetry than nonpsychopathic individuals [152,153]. This finding may occur because symmetry is related to masculinity [110] and masculinity is a product of testosterone. Too much testosterone can lead to a perception of over masculinization which is perceived as threatening and unfriendly and is associated with behavioral problems like excessive aggression [154,155]. Also, symmetry is associated with higher scores on self-report measures of psychological and emotional distress [101]. Developmentally stable, i.e., symmetrical, individuals have better psychological and emotional health.

\section{Conclusions}

Symmetry is associated with many of the correlates of attractiveness. It also affects mate attraction and mate retention related behaviors. Thus, one can conclude that developmental stability plays a major role in attraction and mate retention related behaviors. However, symmetry has not been investigated in relation to all of the correlates of attractiveness. Leg length, hair length and quality, and pupil size have not been investigated in relation to symmetry. Since these are correlates of attractiveness and play a role in mate selection, symmetry may be associated with the perception of these attributes also. Thus, additional research is warranted.

While symmetry plays a role in mate selection and affects many attractiveness related behaviors, the mechanism by which symmetry is detected or comes to influence behavior is not fully clear. A good deal of research shows that women are responding differently to low FA and high FA men. With this in mind two possible explanations regarding the mechanism can be put forth. (1) It is possible that women are assessing the asymmetries directly via some subconscious means of measurement of body parts and facial components. (2) Alternatively, women may be responding to a chemical signal from men such as a pheromone, since research shows that symmetrical men smell better [97], without being consciously aware of this. Of these two explanations the latter has more credibility since prior research shows that symmetry is a correlate of attractiveness, but it is not a cue, i.e., it covaries with cues that women use to determine men's facial attractiveness [110]. Furthermore, the women in the aforementioned research could not rate men's facial symmetry accurately. In this research [110], the relationship between symmetry and attractiveness remained even when symmetry cues were missing, i.e., only the right or left half of faces were presented. Additional evidence supporting the subconscious chemical mechanism for symmetry detection/assessment can also be found in the research showing that: women are best at detecting facial symmetry during the menses phase of their 
cycle, and showing that this heightened ability to detect facial symmetry is not due to greater visual sensitivity during this time [156], and in research showing that ovulating women prefer the scent of symmetrical men $[97,98]$. Overall, the aforementioned research further supports the notion that symmetry is a good genes marker.

\section{References and Notes}

1. Bailey, J.M.; Gaulin, S.; Agyei, Y.; Gladue, B.A. Effects of gender and sexual orientation on evolutionary relevant aspects of human mating psychology. J. Pers. S oc. Psychol. 1994, 66, 1081-1093.

2. Cunningham, M.R. Measuring the physical in physical attractiveness: Quasi experiments on the sociobiology of female facial beauty. J. Pers. Soc. Psychol. 1986, 50, 925-935.

3. Cunningham, M.R.; Barbee, A; Pike, C. What do women want? Facialmetric assessments of multiple motives in the perception of male facial physical attractiveness. J. Pers. So c. Psychol. 1990, 59, 61-72.

4. Cunningham, M.R.; Roberts, A.R.; Barbee, A.P.; Druen, P.B.; Wu, C.-H. Their ideas of beauty are, on the whole, the same as ours: Consistency and variability in the cross cultural perception of female physical attractiveness. J. Pers. Soc. Psychol. 1995, 68, 261-279.

5. Henss, R. "Spieglein, spieglein an der wand..." Geschlech t, alter, und physisc he attraktivitat; Psychologie Verlags Union: Weinhem, Germany, 1992.

6. Henss, R. Waist to hip ratio and attractiveness. Replication and extension. Pers. Individ. Differ. 1995, 19, 479-488.

7. Kenrick, D.T.; Neuberg, S.L.; Zierk, K.L.; Krones, J.M. Evolution and social cognition: Contrast effects as a function of sex, dominance, and physical attractiveness. Pers. Soc. Psychol. Bull. 1994, 20, 210-217.

8. Sadalla, E.K.; Kenrick, D.T.; Vershure, B. Dominance and heterosexual attraction. J. Pers. Soc. Psychol. 1987, 52, 730-738.

9. Singh, D. Adaptive significance of female physical attractiveness: Role of waist-to-hip ratio. $J$. Pers. Soc. Psychol. 1993, 65, 293-307.

10. Singh, D. Is thin really beautiful and good? Relationship between waist-to-hip ratio (WHR) and female attractiveness. Pers. Individ. Differ. 1994, 16, 123-132.

11. Singh, D. Female judgment of male attractiveness and desirability for relationships: Role of waist-to-hip ratio and financial status. J. Pers. Soc. Psychol. 1995, 69, 1089-1101.

12. Singh, D. Female health, attractiveness, and desirability for relationship: Role of breast asymmetry and waist-to-hip ratio. Ethol. Sociobiol. 1995, 16, 465-481.

13. Singh, D.; Luis, S. Ethnic and gender consensus for the effect of waist-to-hip ratio on judgments of women's attractiveness. Hum. Nat. 1995, 6, 51-65.

14. Singh, D.; Young, R.K. Body weight, waist-to-hip ratio, breasts and hips: Role in judgments of female attractiveness and desirability for relationships. Ethol. Sociobiol. 1995, 16, 483-507.

15. Wade, T.J. Evolutionary theory and self-perception: Sex differences in body-esteem predictors of self-perceived physical and sexual attractiveness and self-esteem. Int. J. Psychol. 2000, 35, 36-45. 
16. Wade, T.J. Evolutionary theory and African American self-perception: Sex differences in body esteem predictors of physical and sexual attractiveness, and self-esteem. J. Black Psychol. 2003, 29, 123-141.

17. Symons, D. Beauty is in the adaptations of the beholder: The evolutionary psychology of human female sexual attractiveness. In Sexual Nature/Sexual Culture; Abramson, P.R., Pinkerton, S.D., Eds.; University of Chicago Press: Chicago, IL, USA, 1995; pp. 80-118.

18. Møller, A.P.; Swaddle J.P. Asymmetry, Developmenta l Stability, and Evolution ; Oxford University Press: New York, NY, USA, 1997.

19. Buss, D.M.; Schmitt, D.P. Sexual strategies theory: A contextual evolutionary analysis of human mating. Psychol. Rev. 1993, 100, 204-232.

20. Mazur, A.; Halpern, R.; Udry, R. Dominant looking males copulate earlier. Ethol. Sociobiol. 1994, 15, 87-94.

21. Ehrenkantz, J.; Bliss, E.; Sheard, M.H. Plasma testosterone: Correlation with aggressive behavior and social dominance in man. Psyc. Med. 1974, 36, 469-475.

22. Gladue, E.A.; Boechler, M.; McCaul, K.D. Hormonal response to competition in human males. Aggress. Behav. 1989, 15, 409-422.

23. Kenrick, D.T. Gender, genes and the environment: A biosocial interactionist perspective. In Sex and Gender; Shaver, P., Hendrick, C., Eds.; Sage: Newbury Park, CA, USA, 1987; pp. 14-43.

24. Björntorp, P. Fat cell distribution and metabolism. In Human Obesity; Wurtman, R.J., Ed.; New York Academy of Sciences: New York, NY, USA, 1987; pp. 66-72.

25. Horvath, T. Correlates of physical beauty in men and women. Soc. Behav. Pers. 1979, 7, 145-151.

26. Horvath, T. Physical attractiveness: The influence of selected torso parameters. Arch. Sex. Behav. 1981, 10, 21-24.

27. Booth, A.; Dabbs, J.M., Jr. Testosterone and men’s marriages. Soc. Forces. 1993, 72, 463-477.

28. Sherwood, L. Human Physiology: From Cells to Systems; West: St. Paul, MN, USA, 1989.

29. Gangestad, S.W.; Thornhill, R.; Yeo, R.A. Facial attractiveness, developmental stability and fluctuating asymmetry. Ethol. Sociobiol. 1994, 15, 73-135.

30. Folstad, I.; Karter, A.J. Parasites, bright males and the immunocompetence handicap. Am. Nat. 1992, 139, 603-622.

31. Iwasa, Y.; Pomiankowski, A.; Nee, S. The evolution of costly mate preferences, 11: The handicap principle. Evolution 1991, 45, 1431-1442.

32. Zuk, M. Reproductive strategies and disease susceptibility: An evolutionary viewpoint. Parasitol. Today 1990, 6, 231-233.

33. Björntorp, P. Visceral obesity: A "civilization syndrome". Obes. Res. 1993, 1, 206-222.

34. Rebuffé-Scrive, M.; Marin, P.; Björntorp, P. Effect of testosterone on abdominal adipose tissue in men. Int. J. Obes. 1991, 15, 791-795.

35. Wiggins, J.S.; Wiggins, N.; Conger, J.C. Correlates of heterosexual somatic preference. J. Pers. Soc. Psychol.1968, 10, 82-90.

36. Björntorp, P. The associations between obesity, adipose tissue distribution and disease. Acta Med. Scand. 1988, 222, 121-134.

37. Tovee, M.J.; Cornelissen, P.L. The mystery of female beauty. Nature 1999, 399, 215-216. 
38. Swami, V; Antonakopoulos, N.; Tovee, M.; Furnham, A. A critical test of the waist-to-hip ratio hypothesis of female sexual attractiveness in Britain and Greece. Sex Roles 2006, 54, 201-211.

39. Singh, D.; Randall, P. Beauty is in the eye of the plastic surgeon: Waist-to-hip ratio (WHR) and women's attractiveness. Pers. Individ. Differ. 2007, 43, 329-340.

40. Singh, D; Dixson, B.J.; Jessop, T.S.; Morgan, B.; Dixson, A.F. Cross-cultural consensus for waist-hip ratio and women's attractiveness. Evol. Hum. Behav. 2010, 31, 176-181.

41. Johnston, V.S.; Franklin, M. Is beauty in the eye of the beholder? Ethol. Sociobiol. 1993, 14, 183-199.

42. Kenrick, D.T.; Keefe, R.C. Age preferences in mates reflect sex differences in human reproductive strategies. Behav. Brain Sci. 1992, 15, 75-133.

43. Symons, D. The Evolution of Human Sexuality; Oxford University Press: New York, NY, USA, 1979.

44. Grammer, K.; Fink, B.; Neave, N. Human pheromones and sexual attraction. Eur. J. Obstet. Gynecol. Reprod. Biol. 2005, 118, 135-142.

45. Nettle, D. Women's height, reproductive success, and the evolution of sexual dimorphism in modern humans. Proc. Roy. Soc. London Ser. B 2000, 269, 1919-1923.

46. Nettle, D. Height and reproductive success in a cohort of british men. Hum. Nat. 2002, 13, 473-491.

47. Collins, S.A. Men's voices and women's choices. Anim. Behav. 2000, 60, 773-780.

48. Collins, S.A.; Missing, C. Vocal and visual attractiveness are related in women. Anim. Behav. 2003, 65, 997-1004.

49. Puts, D.A. Mating context and menstrual phase affect women's preferences for male voice pitch. Evol. Hum. Behav. 2005, 26, 388-397.

50. Caryl, P.G.; Bean, J.E.; Smallwood, E.B.; Barron, J.C.; Tully, L.; Allerhand, M. Women’s preferences for male pupil size: Effects of conception risk, and relationship status. Pers. Individ. Differ. 2009, 46, 503-508.

51. Tombs, S.; Silverman, I. Pupillometry: A sexual selection approach. Evol. Hum. Be hav. 2004, 25, 221-228.

52. Hinz, V.; Matz, D.C.; Patience, R.A. Does women's hair signal reproductive potential? J. Exp. Soc. Psychol. 2001, 37, 166-172.

53. Mesko, N.; Bereczkei, T. Hairstyle as an adaptive means of displaying phenotypic quality. Hum. Nat. 2004, 15, 251-270.

54. Sorokowski, P.; Pawlowski, B. Adaptive preferences for leg length in a potential partner. Evol. Hum. Behav. 2008, 29, 86-91.

55. Fessler, D.M.T.; Nettle, D.; Afshar, Y.; Pinheiro, I.D.A.; Bolyanatz, A.; Mulder, M.B.; Cravalho, M.; Delgado, T.; Gruzd, B.; Correia, M.O.; Khaltourina, D.; Korotayev, A.; Marrow, J.; de Souzsa, L.S.; Zbarauskaite, A. A cross-cultural investigation of the role of foot size in physical attractiveness. Arch. Sex. Behav. 2005, 34, 267-276.

56. Livshits, G.; Kobyliansky, E. Study of genetic variance in the fluctuating asymmetry of anthropometrical traits. Ann. Hum. Biol. 1991, 16, 121-129.

57. Grammer, K.; Thornhill, R. Human (Homo sapiens) facial attractiveness and sexual selection: The role of symmetry and averageness. J. Comp. Psychol. 1994, 108, 233-242.

58. Palmer, A.R.; Strobeck, C. Fluctuating asymmetry: Measurement, analysis, pattern. Annu. Rev. Ecol. Syst. 1986, 17, 392-421. 
59. Møller, A.P.; Hoglund, J. Patterns of fluctuating asymmetry in avian feather ornaments: Implications for models of sexual selection. Proc. Roy. Soc. London Ser. B Biol. Sci. 1991, 245, 1-5.

60. Parsons, P.A. Fluctuating asymmetry: An epigenetic measure of stress. Biol. Rev. 1990, 65, 131-145.

61. Hamilton, W.D.; Zuk, M. Heritable true fitness and bright birds: A role for parasites? Science 1982, 218, 384-387.

62. Kowner, R. Facial asymmetry and attractiveness judgement in developmental perspective. $J$. Exp. Psychol. Hum. Percept. Perform. 1996, 22, 662-675.

63. Baudouin, J.-Y.; Tiberghien, G. Symmetry, averageness, and feature size in the facial attractiveness of women. Acta Psychol. 2004, 117, 313-332.

64. Hume, D.K.; Montgomery, R. Facial attractiveness signals different aspects of "quality" in women and men. Evol. Hum. Behav. 2001, 22, 93-112.

65. Penton-Voak, I.S.; Jones, B.C.; Little, A.C.; Baker, S.; Tiddeman, B.; Burt, D.M.; Perrett, D.I. Symmetry, sexual dimorphism in facial proportions and male facial attractiveness. Proc. Roy. Soc. London Ser. B 2001, 268, 1617-1623.

66. Thornhill, R.; Gangestad, S.W. Human facial beauty: Averageness, symmetry, and parasite resistance. Hum. Nat. 1993, 4, 237-270.

67. Fink, B.; Neave, N.; Manning, J.T.; Grammer, K. Facial symmetry and judgements of attractiveness, health and personality. Pers. Individ. Differ. 2006, 41, 491-499.

68. Little, A.C.; Jones, B.C. Evidence against perceptual bias views for symmetry preferences in human faces. Proc. Roy. Soc. London Ser. B 2003, 270, 1759-1763.

69. Rhodes, G.; Yoshikawa, S.; Clark, A.; Lee, K.; McKay, R.; Akamatsu, S. Attractiveness of facial averageness and symmetry in non-Western cultures: In search of biologically based standards of beauty. Perception 2001, 30, 611-625.

70. Watson, P.J.; Thornhill, R. Fluctuating asymmetry and sexual selection. Trends Ecol. Evol. 1994, 9, 21-25.

71. Tovee, M.J.; Tasker, K.; Benson, P.J. Is symmetry a visual cue to attractiveness in the human female body? Evol. Hum. Behav. 2000, 21, 191-200.

72. Manning, J.T.; Koukourakis, K.; Brodie, D.A. Fluctuating asymmetry, metabolic rate and sexual selection in human males. Evol. Hum. Behav. 1997, 18, 15-21.

73. Møller, A.P.; Soler, M.; Thornhill, R. Breast asymmetry, sexual selection, and human reproductive success. Ethol. Sociobiol. 1995, 16, 207-219.

74. Leary, R.F.; Allendorf, F.W. Fluctuating asymmetry as an indicator of stress: Implications for conservation biology. Trends Ecol. Evol. 1989, 4, 214-217.

75. Parsons, P.A. Fluctuating asymmetry: A biological monitor of environmental and genomic stress. Heredity 1992, 68, 361-364.

76. Alexander, R.D. The search for an evolutionary philosophy of man. Proc. Roy. Soc. Vict. 1971, 84, 99-120.

77. Low, B. Sexual selection and human ornamentation. In Evolutionary Biology and Human Social Behavior; Chagnon, N.A., Irons, W., Eds.; Duxbury Press: North Scituate, MA, USA, 1979; pp. 462-487.

78. Cant, J.G.H. Hypothesis for the evolution of human breasts and buttocks. Amer. Nat. 1981, 117, 199-204. 
79. Gallup, G.G. Unique features of human sexuality in the context of evolution. In Alternative Approaches to Study of Sexual Behavior ; Byrne, D., Kelley, K., Eds.; Lawrence Erlbaum: New York, NY, USA, 1986; pp. 13-41.

80. Low, B.; Alexander, R.D.; Noonan, K.M. Human hips, breasts and buttocks: Is fat deceptive? Ethol. Sociobiol. 1987, 8, 249-257.

81. Møller, A.P.; Pomiankowski, A. Fluctuating asymmetry and sexual selection. Genetica 1993, 89, 267-279.

82. Singh, D. Female health, attractiveness, desirability for relationships: Role of breast asymmetry and waist to hip ratio. Ethol. Sociobiol. 1995, 16, 465-481.

83. Maliniac, J.W. Breast Deformities and Their Repair; Grune and Stratton: New York, NY, USA, 1950.

84. Feinberg, D.R.; Jones, B.C.; DeBruine, L.M.; Moore, F.R.; Smith, M.J.L.; Cornwell, R.E.; Tiddeman, B.P.; Boothroyd, L.G.; Perrett, D.I. The voice and face of woman: One ornament that signals quality? Evol. Hum. Behav. 2005, 26, 398-408.

85. Hughes, S.M.; Dispenza, F.; Gallup, G.C., Jr. Ratings of voice attractiveness predict sexual behavior and body configuration. Evol. Hum. Behav. 2004, 25, 295-304.

86. Beckford, N.S.; Schain, D.; Roor, S.R.; Schanbacher, B. Androgen stimulation and laryngeal development. Ann. Otol. Rhinol. Laryngol. 1985, 94, 634-640.

87. Fant, C. Acoustic Theory of Speech Production; Mouton: The Hague, The Netherlands, 1960.

88. Hollien, H. Some laryngeal correlates of vocal pitch. J. Speech Hear. Res. 1960, 3, 52-58.

89. Hughes, S.M.; Harrison, M.A.; Gallup, G.G., Jr. The sound of symmetry: Voice as a marker of developmental stability. Evol. Hum. Behav. 2002, 23, 173-180.

90. Thornhill, R.; Gangestad, S.W. Evolutionary theory led to evidence for a male sex pheromone that signals symmetry. Psychol. Inq. 2003, 14, 318-325.

91. Herz, R.S.; Cahill, E.D. Differential use of sensory information in sexual behavior as a function of gender. Hum. Nat. 1997, 8, 275-286.

92. Regan, P.C.; Berscheid, E. Gender differences in beliefs about the causes of male and female sexual desire. Pers. Relatsh. 1995, 2, 345-358.

93. Gower, D.B.; Ruperelia, B.A. Olfaction in humans with special reference to odorous 16-androstenes: Their occurrence, perception and possible social, psychological and sexual impact. J. Endocrinol. 1993, 137, 167-187.

94. Pause, B.M.; Sojka, B.; Krauel, K.; Fehmwolfsdorf, G.; Ferstl, R. Olfactory informationprocessing during the course of the menstrual cycle. Biol. Psychol. 1996, 44, 31-54.

95. Thornhill, R.; Gangestad, S.W.; Miller, R.; Scheyd, G.; McCollough, J.K.; Franklin, M. Major histocompatibility genes, symmetry and body scent attractiveness in men and women. Behav. Ecol. 2003, 14, 668-678.

96. Gangestad, S.W.; Thornhill, R. Menstrual cycle variation in women's preference for the scent of symmetrical men. Proc. Roy. Soc. London Ser. B 1998, 265, 927-933.

97. Thornhill, R.; Gangestad, S.W. The scent of symmetry: A human sex pheromone that signals fitness? Evol. Hum. Behav. 1999, 20, 175-201.

98. Rikowski, A.; Grammer, K. Human body odour, symmetry and attractiveness. Proc. Roy. Soc. London Ser. B 1999, 266, 869-874. 
99. Buss, D.M. Sex differences in human mate preferences: Evolutionary hypotheses tested in 37 cultures. Behav. Brain Sci. 1989, 12, 1-49.

100. Gangestad, S.W.; Thornhill, R. The evolutionary psychology of extrapair sex: The role of fluctuating asymmetry. Evol. Hum. Behav. 1997, 18, 69-88.

101. Shackelford, T.K.; Larsen, R.J. Facial asymmetry as an indicator of psychological, emotional, and physiological distress. J. Pers. Soc. Psychol. 1997, 72, 456-466.

102. Shackelford, T.K.; Larsen, R.J. Facial attractiveness and physical health. Evol. Hum. Behav. 1999, 20, 71-76.

103. Waynforth, D. Fluctuating asymmetry and human male life history traits in rural Belize. Proc. Roy. Soc. London Ser. B 1998, 265, 1947-1501.

104. Bates, T.C. Fluctuating asymmetry and intelligence. Intelligence 2007, 35, 41-46.

105. Furlow, F.B.; Armijo-Pruett, T.; Gangestad, S.W.; Thornhill, R. Fluctuating asymmetry and psychometric intelligence. Proc. Roy. Soc. London Ser. B 1997, 264, 1-8.

106. Luxen, M.F.; Buunk, A.P. Human intelligence, fluctuating asymmetry and the peacock's tail: General intelligence (g) as an honest signal of fitness. Pers. Individ. Differ. 2006, 41, 897-902.

107. Smith, R.L. Human Sperm Competition. In Sperm Compet ition and the Evolution of Animal Mating Systems; Smith, R.L., Ed.; Academic Press: London, UK, 1984; pp. 601-660.

108. Thornhill, R.; Gangestad, S.W.; Comer, R. Human female orgasm and mate fluctuating asymmetry. Anim. Behav. 1995, 50, 1601-1615.

109. Baker, R.R.; Bellis, M.A. Human sperm competition: Ejaculate manipulation by females and a function for the female orgasm. Anim. Behav. 1993, 46, 887-909.

110. Scheib, J.E.; Gangestad, S.W.; Thornhill, R. Facial attractiveness, symmetry and cues of good genes. Proc. Roy. Soc. London Ser. B 1999, 266, 1913-1917.

111. Manning, J.T.; Scutt, D.; Lewis-Jones, D.I. Developmental stability, ejaculate size and sperm quality in men. Evol. Hum. Behav. 1998, 19, 273-282.

112. Baker, R.R. Copulation, masturbation and infidelity: State-of-the-art. In New Aspects of Huma $n$ Ethology; Schmitt, A., Atzwanger, K., Grammer, K., Schafer, K., Eds.; Plenum Press: New York, NY, USA, 1997; pp.163-188.

113. Curran, J.P.; Lippold, S. The effects of physical attraction and attitude similarity on attraction in dating dyads. J. Per. 1975, 43, 528-539.

114. Thornhill, R.; Gangestad, S.W. Human fluctuating asymmetry and sexual behavior. Psychol. Sci. 1994, 5, 297-302.

115. Møller, A.P.; Thornhill, R. Bilateral symmetry and sexual selection: A meta-analysis. Am. Nat. 1997, 151, 174-192.

116. Hite, S. Women and Love: A Cultural Revolution in Progress; Knopf: New York, NY, USA, 1987.

117. Kinsey, A.C.; Pomeroy, W.B.; Martin, C.E.; Gebhard, P.H. Sexual Behavior in the Human Female; W. B. Saunders: Philadelphia, PA, USA, 1953.

118. Laumann, E.O.; Gagnon, J.H.; Michael, R.T.; Michaels, S. The Social Organization of Sexuality; University of Chicago Press: Chicago, IL., USA, 1994.

119. Kinsey, A.C.; Pomeroy, W.B.; Martin, C.E. Sexual Behavior in the Human Male; W. B. Saunders: Philadelphia, PA, USA, 1948.

120. Thompson, A.P. Extramarital sex: A review of the research literature. J. Sex Res. 1983, 19, 1-22. 
121. Benshoof, L.; Thornhill, R. The evolution of monogamy and concealed ovulation in humans. J. Soc. Biol. Struc. 1979, 2, 95-106.

122. Buss, D.M. From vigilance to violence: Tactics of mate retention in American undergraduates. Ethol. Sociobiol. 1988, 9, 291-317.

123. Buss. D.M.; Dedden, L.A. Derogation of competitors. J. Soc. Per. Relat. 1990, 7, 395-422.

124. Durante, K.M.; Li, N.; Haselton, M.G. Changes in women's choice of dress across the ovulatory cycle: Naturalistic and laboratory task-based evidence. Pers. Soc. Psychol. Bull. 2008, 34, 1451-1460.

125. Haselton, M.G.; Mortezaie, M.; Pillsworth, E.G.; Bleske, A.E.; Frederick, D.A. Ovulatory shifts in human female ornamentation: Near ovulation, women dress to impress. Horm. Behav. 2007, $51,40-45$.

126. Roder, S.; Brewer, G.; Fink, B. Menstrual cycle shifts in women's self-perception and motivation: A daily report method. Pers. Individ. Differ. 2009, 47, 616-619.

127. Manning, J.T.; Pickup, L.J. Symmetry and performance in middle distance runners. Int. J. Sport. Med. 1998, 19, 1-5.

128. Manning, J.T. Digit Ratio: A Pointer to Fertility, Behavior and Health; Rutgers University Press: Piscataway, NJ, USA, 2002.

129. Manning, J.T; Barley, L.; Walton, J.; Lewis-Jones, D.I.; Trivers, R.L.; Singh, D.; Thornhill, R.; Rohde, P.; Bereczkei, T.; Henzi, P.; Soler, M.; Szwed, A. The 2nd:4th digit ratio, sexual dimorphism, population differences, and reproductive success: Evidence for sexually antagonistic genes? Evol. Hum. Behav. 2000, 21, 163-183.

130. Garn, S.M.; Burdi, A.R.; Babler, W.J.; Stinson, S. Early prenatal attainment of adult metacarpalphalangeal ranking and proportions. Am. J. Phys. Anthropol. 1975, 43, 327-332.

131. Manning, J.T.; Scutt, D.; Wilson, J.; Lewis-Jones, D.I. The ratio of 2nd to 4th digit length: A predictor of sperm numbers and concentrations of testosterone, luteinizing hormone, and oestrogen. Hum. Reprod. 1998, 13, 3000-3004.

132. Phelps, V.R. Relative index finger length as a sex-influenced trait in man. Am. J. Hum. Genet . 1952, 4, 72-79.

133. Manning, J.T.; Taylor, R.P. Second to fourth digit ratio and male ability in sport: Implications for sexual selection in humans. Evol. Hum. Behav. 2001, 22, 61-69.

134. Robinson, S.J.; Manning, J.T. The ratio of 2nd to 4th digit length and male homosexuality. Evol. Hum. Behav. 2000, 21, 333-345.

135. Wade, T.J.; Shanley, A.; Imm, M. Second to fourth digit ratio and individual differences in women's self-perceived attractiveness, self-esteem and body-esteem. Pers. Individ. Differ. 2004, 37, 799-804.

136. Hönekopp, J.; Manning, J.T.; Muller, C. Digit ratio (2D:4D) and physical fitness in males and females: Evidence for effects of prenatal androgens on sexually selected traits. Horm Behav. 2006, 49, 545-549.

137. Sluming, V.A.; Manning, J.T. Second to fourth digit ratio in elite musicians: Evidence for musical ability as an honest signal of male fitness. Evol. Hum. Behav. 2000, 21, 1-9.

138. Manning, J.T.; Quinton, S. Association of Digit Ratio (2D:4D) with self-reported attractiveness in men and women: Evidence from the BBC internet survey. J. Individ. Differ. 2007, 28, 73-77. 
139. Roney, J.R.; Maestripieri, D. Relative digit length predicts men's behavior and attractiveness during social interactions with women. Hum. Nat. 2004, 15, 271-282.

140. Saino, N.; Romano, M.; Innocenti, P. Length of ring fingers differentially influence sexual attractiveness of men's and women's hands. Behav. Ecol. Sociobiol. 2006, 60, 447-454.

141. Fink, B.; Manning, J.T.; Neave, N.; Grammer, K. Second to fourth digit ratio and facial asymmetry. Evol. Hum. Behav. 2004, 25, 125-132.

142. Darwin, C.R. The Descent of Man and Selection in Relation to Sex ; D. Appleton and Company: New York, NY, USA, 1871.

143. Brown, W.M.; Cronk, L.; Grochow, K,; Jacobson, A.; Liu, C.K.; Popovic, Z.; Trivers, R. Dance reveals symmetry especially in young men. Nature 2005, 438, 1148-1150.

144. Wade, T.J.; Weinstein, E.; Dalal, N. Are there personality and attractiveness halo effects associated with dancing ability? Unpublished manuscript, 2010.

145. Botwin, M.D.; Buss, D.M.; Shackelford, T.K. Personality and mate preferences: Five factors in mate selection and marital satisfaction. J. Pers. 1997, 65, 107-136.

146. Hassin, R.; Trope, Y. Facing faces: Studies on the cognitive aspects of physiognomy. J. Pers. Soc. Psychol. 2000, 78, 837-852.

147. Todorov, A.; Mandisodza, A.N.; Goren, A.; Hall C.C. Inferences of competence from faces predict election outcomes. Science 2005, 308, 1623-1626.

148. Kenny, D.A.; Albright, L.; Malloy, T.E.; Kashy, D.A. Consensus in interpersonal perception: Acquaintance and the big five. Psychol. Bull. 1994, 116, 245-258.

149. Pound, N.; Penton-Voak, I.S.; Brown, W.M. Facial symmetry is positively associated with selfreported extraversion. Pers. Individ. Differ. 2007, 43, 1572-1582.

150. Fink, B.; Neave, N.; Manning, J.T.; Grammer, K. Facial symmetry and the 'big-five’ personality factors. Pers. Individ. Differ. 2005, 39, 523-529.

151. Noor, F.; Evans, D.C. The effect of facial symmetry on perceptions of personality and attractiveness. J. Res. Pers. 2003, 37, 339-347.

152. Lalumeire, M.L.; Harris, G.T.; Rice, M.E. Psychopathy and developmental instability. Evol. Hum. Behav. 2001, 22, 75-92.

153. Reilly, J.L.; Murphy, P.T.; Byrne, M.; Larkin, C.; Gill, M.; O’Callaghan, E.; Lane, A. Dermatoglyphic fluctuating asymmetry and atypical handedness in schizophrenia. Schizophr. Res. 2001, 50, 159-186.

154. Johnston, V.S.; Hagel, R.; Franklin, M.; Fink, B.; Grammer, K. Male facial attractiveness: Evidence for hormone mediated adaptive design. Evol. Hum. Behav. 2001, 22, 251-267.

155. Wade, T.J.; Dyckman, K.A.; Cooper, M. Invisible men: Evolutionary theory and attractiveness and personality evaluations of 10 African American male facial shapes. J. Black Psyc. 2004, 30, 477-488.

156. Oinonen, K.A.; Mazmamian, D. Facial symmetry detection ability changes across the menstrual cycle. Biol. Psychol. 2007, 75, 136-145.

(C) 2010 by the authors; licensee MDPI, Basel, Switzerland. This article is an Open Access article distributed under the terms and conditions of the Creative Commons Attribution license (http://creativecommons.org/licenses/by/3.0/). 